\title{
Review: family or couples therapy is more effective than non-family therapy for drug abuse
}

\author{
Stanton MD, Shadish WR. Outcome, attrition, and family-couples treatment for drug abuse: A meta-analysis and review of the \\ controlled, comparative studies. Psychol Bull 1997 Sep;122:170-91.
}

\section{Question}

In people who are drug abusers, what is the effectiveness of family or couples therapy?

\section{Data sources}

Studies were identified by searching Dissertation Abstracts International, Psychological Abstracts, and other computerised bibliographies; reviewing personal reprint files; and contacting experts in the field.

\section{Study selection}

Studies were selected if they were randomised trials pertaining to the use, abuse of, or addiction to $\geqslant 1$ illicit drug and at least 1 of the comparison groups involved family or couples therapy. Studies that primarily examined alcohol abuse were excluded.

\section{Data extraction}

Data were extracted on patient characteristics, study design quality (maximum 30 points), sample size, study duration, and dropout and attrition issues. Treatment conditions that were considered included use of a treatment manual, treatment setting (university or community based), whether the treatment challenged methadone, and the nature of alternative therapies (non-family: individual counselling, peer group therapy, and treatment as usual; and other family oriented: psychoeducation and relatives' groups). Effect size was reported as the standardised mean difference between comparison groups. Effect sizes were also calculated to take into account dropouts and total attrition.

\section{Main results}

A meta-analysis was done. 15 studies were included involving 3483 participants (index patients plus family members). The median design quality score was 25.0. Thirteen studies compared family or couples therapy with non-family or non-couples therapy. Patients who received family or couples therapy had a greater decrease in drug use than did patients who received non-family therapy (effect size $0.48, \mathrm{p}<0.01$ ). The difference remained statistically significant when dropouts and total attrition were taken into account. Family therapy was effective in both adults ( 6 studies) (effect size $0.42, \mathrm{p}<0.01$ ) and adolescents (7 studies) (effect size 0.39, $\mathrm{p}<0.01)$. 4 studies comparing family therapy with family psychoeducation showed family therapy to be more effective (effect size $0.66, \mathrm{p}<0.01$ ). Family therapy was not superior to relatives' groups (2 studies) (effect size -0.04). Only 2 studies compared different types of family therapy (both in adolescents) and the difference between treatment groups did not reach statistical significance (effect size $-0.01)$.

\section{Conclusion}

Family or couples therapy is effective for drug abuse and gives superior results compared with such non-family approaches as individual counselling and peer group therapy.

\section{Source of funding: not stated.}

For reprint and correspondence:Dr M D Stanton, Dean, School of Professional Psychology and Social Work, Spalding University, 851 South Fourth Street, Louisville, KY 40203-2188, USA. Fax +1502 5857159

\section{Commentary}

This comprehensive review by Stanton and Shadish pulls together a disparate literature and makes a major point that has not received the attention it deserves to date. Stanton has been a longtime proponent of family therapy approaches to addiction, and this paper provides a masterly overview of a surprisingly extensive literature.

The authors contacted key researchers and conducted electronic searches. There may be other unpublished studies that could be incorporated into further reviews following systematic hand searches of the published and grey literature. Such an activity may be possible in the relatively near future due to the development of a trials register in the Rome based Co- chrane Review group on alcohol and other drugs.

The authors have had a particularly difficult task in controlling for (a) different approaches to family therapy, (b) different objectives of trials, and (c) different outcome criteria. To contend with some of these inherent difficulties, the studies were given quality ratings. In addition, the authors concentrate a major part of their text on treatment retention and show a substantial effect of family therapy in improving retention. Given the fact that treatment retention in many settings is regarded as one of the major outcome objectives, these findings are striking and of considerable treatment and policy importance. As well as exploring the potential effect on treatment retention, such studies suggest a major area of exploration in evaluating the effect of recruiting clients who are difficult to engage through family therapy or other family intervention processes. Given the data presented here, it will be interesting to revisit this area in the next few years and see whether reviews such as this have stimulated further development and evaluation of family intervention approaches.

Michael Farrell, MRCP, MRCPsych John Strang, MD, FRCPsych Institute of Psychiatry National Addiction Centre London, UK 